\title{
ESPAÇO FUNCIONAL DO GRUPO DE ENFERMAGEM NOS CUIDADOS PRIMÁRIOS DE SAƯDE *
}

\author{
Nilce Piva Adami**
}

ADAMI, N. P. Espaço funcional do grupo de enfermagem nos cuidados primários de saúde. Rev. Esc. Enf. USP, São Paulo, 15(2):179-182, 1981.

A autora relaciona as atividades que vem sendo desenvolvidas pelo pessoal de enfermagem ao nível de cuidados primários em serviços básicos de saúde. Comenta, também, obstáculos a serem superados para a efetiva participação desse pessoal no primeiro nivel de assistência à saúde ofertados à população.

\section{INTRODUÇÃO}

BRAVO $^{2}$ considera que um sistema de saúde regionalizado deve existir em função de:

- oferecer cobertura universal, possibilitando o acesso da população ao tipo de assistência mais adequada a seu estado de saúde, doença ou invalidez;

- prover assistência integral de saúde, eliminando barreiras econômicas, espaciais e culturais;

- reduzir os custos assistenciais, utilizando de preferência os serviços de cuidados primários e ambulatoriais, reservando a assistência hospitalar para os pacientes que dela necessitarem de forma indiscutivel;

- descentralizar a assistência de saúde, mediante um sistema de niveis de atendimento hierarquizado, desenhado de tal modo que todos os serviços, desde os mais simples até os mais especializados, sejam acessiveis para quem deles necessitar, por meio de um esquema de referência;

- organizar a equipe de saúde, compondo-a de profissionais, técnicos e auxiliares de diversas disciplinas, de forma a que esses elementos sejam responsáveis pela saúde da comunidade. Para o bom êxito do trabalho programado, as atividades dessa equipe devem ser coordenadas por meio de ações efetivas de comunicação $e$ supervisão.

Neste modelo de assistência regionalizada, o nível periférico do sistema tem por competência funcional a provisão de cuidados de primeira linha à população, englobando dois sub-niveis a saber:

- assistência primária elementar, prestada por pessoal auxiliar que atua em postos de saúde; $\mathbf{e}$

* Parte do trabalho apresentado no Simpósio "Participaçăo da enfermeira na Assisténcia Primária de Saude", realizado na 42.a Semana de Enfermagem da ABEn - Seção e Distrito de São Paulo, 1981.

* * Professor Assistente Doutor do Departamento de Prática de Saúde Pública da Faculdado de Saúdo Publica da USP. 
- assistência primária mais diferenciada, proporcionada por uma equipc integrada por profissionais e elementos auxiliares, responsáveis pelas ações nucleares previstas na programação de trabalho de centros de saúde.

\section{ATUAÇÃO DO GRUPO DE ENFERMAGEM}

A análise do elenco de atividades que são próprias do nível primário, realizadas tanto em postos como em centros de saúde, indica a existência e a predominância de ações típicas da área de enfermagem. Este fato, aliado a um processo histórico verificado nos serviços de saúde, comprova a existência de um espaço funcional ocupado de fato pelo pessoal desse grupo profissional. No entanto, o pleno aproveitamento funcional dessas categorias de pessoal, deveria ser objeto de estudos, tendo em vista a racionalização do desenvolvimento e operação dos serviços básicos, conforme já foi preconizado por RIBEIRO \& OLIVEIRA ${ }^{4}$ num documento conjunto do COFEN e ABEn, sobre a enfermagem no Projeto do PREV-SAÚDE.

Sem entrar em detalhes, mas procurando visualizar o panorama observado em alguns serviços básicos de saúde, é possível relacionar as seguintes ações, como trabalho desenvolvido pelo grupo de enfermagem ${ }^{1,3}$ :

- controle sistematizado de gestantes e crianças sadias, de pacientes com determinadas doenças transmissiveis e crônicas, com especial atenção para a detecção de riscos mediante a aplicação de critérios estabelecidos. Vale ressaltar que a Fundação SESP teve a primazia de iniciar a simplificação das ações de saúde, introduzindo a partir de 1958 o atendimento de enfermagem ao grupo maternoinfantil. Devido aos bons resultados alcançados com essa experiência, incorporou posteriormente a atividade em tela, no controle da tuberculose e da hanseníase;

- identificação e tratamento padronizado de afecções e traumatismos mais comuns, com encaminhamento a outros níveis assistenciais, segundo a avaliação de cada caso;

- promoção da melhoria alimentar para os grupos de alto risco (gestantes, nutrizes e crianças);

- aplicação de vacinas básicas e especiais, visitas domiciliares, de tratamentos e seu controle;

- realização de alguns exames laboratoriais simples, além da colheita e envio de material ao laboratório de referência;

- educação em aspectos de saúde para indivíduos e grupos da comunidade tendo em vista facilitar adaptações voluntárias a comportamentos na área da saúde;

- promoção da articulação do sistema formal de saúde com o informal por meio da valorização da atuação de agentes tradicionais da comunidade, como a "curiosa". Este trabalho tem por objetivo a prática não lesiva dessas pessoas, afim de melhorar, desta forma, a assistência à parturiente de baixo risco materno-fetal e ao recém-nascido.

Quanto à enfermeira, em virtude de sua dependência de alguns fatores (pessoais, profissionais e institucionais), tem exercido predominantemente seus papéis 
tradicionais: gerência, treinamento e supervisão. Quanto à sua atuação em papéis ampliados, algumas experiências vêm demonstrando a excelência do seu desempenho, como por exemplo no Serviço de Enfermagem de Saúde Pública do Hospital de Clínicas de Porto Alegre ${ }^{5}$, onde essa profissional presta assistência direta à população materno-infantil e a grupos com doenças crônicas estabilizadas.

\section{COMENTÁRIOS FINAIS}

Finalizando, é válida a colocação de alguns pontos para reflexão quanto a obstáculos a serem superados para a efetivação dos cuidados primários e a adequação da participação do pessoal de enfermagem nesse nível de atendimento, tais como ${ }^{4,6,7}$ :

1. Se bem que simples, a rede básica, do ponto de vista técnico apresenta algumas complexidade no aspecto prático, como por exemplo resistência à sua implantação, devido a: de; e

- dificuldades na integração e coordenação inter e intra-instituições de saú-

- resistência à adequação da tecnologia existente à adoção de tecnologia mais simples e de métodos não tradicionais, principalmente os voltados para a desconcentração do saber.

2. Apoio legal para o exercício profissional da enfermagem em face da nova filosofia de trabalho dos serviços básicos de saúde. A legislação da prática profissiona vigente desde 1955 não previu, de direito, a assunção de novos papéis que no momento já estão sendo assumidos de fato.

3. Redefinição e operacionalização das funções da enfermeira, considerada sua ampliação, para que, desta forma, sejam evitadas possiveis atitudes monopolistas de profissionais de saúde, quanto à delimitação de atividades.

4. Ampliação do número de cargos para o pessoal de enfermagem - oferta ora concentrada em serviços hospitalares principalmente - a fim de atender às novas propostas dos serviços básicos de saúde.

5. Alterações no sistema formal de preparo de recursos humanos de enfermagem, quanto aos seus objetivos e conteúdo teórico-prático, atualmente centrados em experiências de aprendizagem voltadas para a recuperação da saúde.

6. Incorporação, na prática profissional, dos achados de estudos científicos, a fim de que possa ser comprovada a eficácia de experiências colocadas em prática. A utilização desses achados permitirá a demonstração do efeito das intervenções da enfermagem de caráter tanto assistencial como administrativo.

ADAMI, N. P. The role of the nursing group in the primary health care. Rev. Esc. Enf. USP, São Paulo, 15(2):179-182, 1981.

The author relates the activities developed by the nursing personnel at the primary care level of basic health services. She also describes comments some obstacles to be overcome for the effective participation of this personnel in first level of the health care offered to the population. 


\section{REFERENGIAS BIBLIOGRAFICAS}

1. ADAMI, N. P. Aspectos teóricos dos cuidados primários de saude. Rev. Esc. Enf. USP, Såo Paula, 14 (3): $229-35,1980$.

2. BRAVO, A. L. Planificacion regional de las instalaciones de salud. Parte I: Desde el punto de vista del planificador de atención de la salud. In: KLECZKOWSKI, B. M. \& PIBOULEAU, R., eds. Critérios de planificacion e diseño de instalaciones de atencion de la salud en los paises en de. sarollo. Whashington, Organizacion Panamericana de la Salud, 1979. v. 2, p. 9-28. (Publicación cientifica 382).

3. CASTRO, I. B. Estudo explorativo sobre a consulta de enfermagem. Rev. Bras. Enf., Brasilia, 28 (4): 76-94, 1975 .

4. ENFERMAGEM no projeto do Prevsaúde. Rio de Janeiro, Conselho Federal de Enfermagem/Associacão Brasileira de Enfermagem, 1980 (mimeografado).

5. MUXFELDT, L. C. F. Contribuição para o planejamento do serviço de enfermagem em saúde pública no Hospital das Clínicas de Porto Alegre: análise da atençāo de enfermagem em saúde pública. São Paulo, 1978. (Dissertação de Mestrado - Faculdade de Saúde Pública da USP).

6. PAIM, L. Recursos humanos de enfermagem e serviços básicos de saúde. In: CONFERENCIA NACIONAL DE SAƯDE, 7.2, Brasília, 1980. Anais. Brasilia, Ministério da Saúde, 1980. p. 131-3.

7. SANTOS, N. R. Atenção primária em saúde - um posicionamento. Campinas, 1979 (mimeografado). 